\title{
Community acquired pneumonia in diabetic and non-diabetic hospitalized patients: presentation, causative pathogens and outcome
}

\author{
Saibal MAA ${ }^{1}$, Rahman $\mathrm{SHZ}^{2}$, Nishat L ${ }^{3}$, Sikder $\mathrm{NH}^{4}, \mathrm{Begum} \mathrm{SA}^{5}$, Islam $\mathrm{MJ}^{6}, \mathrm{Uddin}_{\mathrm{KN}^{7}}$ \\ ${ }^{I}$ Department of Medicine, Eastern Medical College Hospital, Comilla, ${ }^{2}$ Immunology \& Molecular \\ Biology, National Institute of Cancer Research \& Hospital (NICRH), Dhaka, ${ }^{3}$ Department of Anatomy, \\ Bangabandhu Sheikh Mujib Medical University (BSMMU), Dhaka, ${ }^{4}$ Neurology, Northern \\ International Medical College, Dhaka, ${ }^{5}$ Department of Radiology \& Imaging, Bangladesh Institute of \\ Research and Rehabilitation in Diabetes, Endocrine \& Metabolic Disorders (BIRDEM), Dhaka, \\ ${ }^{6}$ Cancer Epidemiology, NICRH, Dhaka, ${ }^{7}$ Internal Medicine, BIRDEM, Dhaka. \\ Email: saibalakbar@yahoo.com
}

\begin{abstract}
Both community acquired pneumonia and diabetes mellitus are common in Bangladesh. Though hospitalization of diabetic patients with CAP is increasing, data regarding their clinical presentation, microbial characteristics, antimicrobial susceptibility and outcome are lacking. This study was aimed at finding any difference in clinical presentation, bacterial causes, antimicrobial susceptibility pattern of isolated bacteria and outcome in diabetic and non-diabetic hospitalized patients with CAP. In this study total 47 diabetic and 43 non-diabetic adult hospitalized patients with CAP were enrolled. Clinical presentation of CAP differed in diabetics and non-diabetics. Frequency of atypical presentation and CURB-65 score were significantly higher in diabetics. Pleural effusion with multilobar infiltration was also common feature for CAP in diabetic patients. Klebsiella pneumoniae was the most frequent causative pathogen for CAP in diabetic patients, whereas Streptococcus pneumoniae was the most frequent causative agent for non-diabetic patients. Bacteria isolated from sputum sample of diabetic patients with CAP were resistant to almost all recommended antibiotics used for CAP but $100 \%$ of isolates were sensitive to Carbapenems. Pulmonary complications were relatively more in diabetics than in non-diabetics. Hospitalized diabetics with CAP required referral to intensive care unit more than that of non-diabetics. So, diabetic patients with CAP need extra attention.
\end{abstract}

\section{Introduction}

Community acquired pneumonia (CAP) is the lower respiratory tract infection acquired outside the hospital or long term health care facility. It is diagnosed in the community or within 48 hours of admission in the hospital ${ }^{\mathbf{1 , 2}}$. CAP is usually acquired through droplet infection. Once organisms settle in the alveoli, an inflammatory response ensues. The classical pathological response evolves through the phases of congestion, red and grey hepatisation and finally resolution with little or no scarring. Death rates in hospital admitted patients are between $5-10 \%$ but may be as high as $50 \%$ in severe illness $\mathbf{3}$.

Diabetes mellitus (DM) is a group of metabolic disorder characterized by a state of chronic hyperglycaemia resulting from defect in insulin secretion, insulin action or both. Its prevalence posed a serious threat to the entire population of the world ${ }^{4}$. In 2000 Bangladesh had 3.2 million people with diabetes 5 . Pathogenesis of the major long-term complications of DM is due to both microangiopathic process and non-enzymatic glycosylation of tissue protein. A wide range of function of neutrophil and macrophage are impaired in DM. These include chemotaxis, adherence, phagocytosis and the ability to kill the phagocytosed microorganism. Reduction in intracellular killing of microbes with free radicals superoxides and hydrogen peroxide called the respiratory burst are also impaired ${ }^{6}$. Disturbances in acquired immunity also occur in diabetic patients ${ }^{\mathbf{7 , 8}}$. Alteration in the function of capillary endothelium, the rigidity of red blood cells and changes in the oxygen dissociation curve that occur as a result of chronic hyperglycaemia may affect the hosts' ability to combat infections. As a result patients with long-term diabetes mellitus are more prone to infections than non-diabetic patients? Staphylococcus aureus is the major pathogen in the aetiology of both CAP and nosocomial pneumonia in diabetic patients ${ }^{10,11}$. Bacterial pneumonia in diabetic individuals when caused by Klebsiella pneumoniae and Staphylococcus aureus is associated with more severe course and need frequent mechanical ventilator support ${ }^{12}$. Though hospitalization of diabetic patients with CAP are 
increasing in Bangladesh, information regarding their clinical presentation, microbiological characteristics, antimicrobial susceptibility pattern that is required for choosing empiric antibiotic treatment and outcome of patients are lacking. This study was aimed at finding any difference in clinical presentation, bacterial causes, antimicrobial susceptibility pattern of isolated bacteria and immediate outcome in diabetic and non-diabetic hospitalized patients with CAP.

\section{Materials and Methods}

This prospective observational study was carried out in the Department of Internal Medicine and Department of Pulmonology of Bangladesh Institute of Research \& Rehabilitation in Diabetes, Endocrine \& Metabolic Disorders (BIRDEM) in collaboration with National Institute of Diseases of Chest \& Hospital (NIDCH) and Dhaka Medical college Hospital (DMCH) between February to November 2009. The study was approved by the Ethical Review Committee of Bangladesh Diabetic Association and informed consent was taken from each patient before their enrollment in the study. Total 47 diabetic and 43 non-diabetic adult hospitalized patients with CAP were enrolled in the study. Sampling was convenient and purposive. Patients under 18 years and over 80 years, having acid fast bacilli (AFB) in sputum, having bronchial carcinoma, chronic renal disease stage 4 or 5 , heart failure and patients with pregnancy were excluded. For each enrolled patient complete clinical history was taken and physical examination was done, complete blood count, biochemical tests, chest radiograph and sputum Gram stain, AFB and culture \& sensitivity examination was done. CAP was defined as the presence of an acute illness with two or more of the symptoms and signs of lower respiratory tract infection: fever, new or increasing cough or sputum production, dyspnoea, chest pain and new focal sign on chest examination and presence of infiltration in the chest radiograph on or within 48 hours of admission that was consistent with acute infection. DM status was determined on the basis of current or previous biochemical diagnosis of DM according to WHO definition ${ }^{4}$ with or without treatment with antidiabetic agents. Validated CAP severity index, CURB-65 scoring was done by calculating scores on confusion of new onset (Mini mental state score $\leq 8$ ), blood urea nitrogen (BUN) level ( $\geq 7 \mathrm{mmol} / \mathrm{L})$, respiratory rate $(\geq 30 / \mathrm{min})$ and presence of hypotension (systolic blood pressure $<90 \mathrm{~mm}$ of $\mathrm{Hg}$ and diastolic blood pressure $<60 \mathrm{~mm}$ of $\mathrm{Hg}$ ) on admission and age $\left(\geq 65\right.$ years) ${ }^{14}$. Other vital signs such as temperature, pulse rate were recorded accordingly. Chest X-ray was interpreted by the radiologist who was unaware of patients' clinical condition. The presence of comorbid conditions was determined by patient's reports and medical records reviews. From each patient, sputum was collected in a wide mouth container, cultured in blood agar and MacConkey's agar media at $37^{\circ} \mathrm{C}$ for up to 48 hours in the Microbiology Laboratory of BIRDEM Hospital. Positive growth was identified by colony characteristics and biochemical tests. Antimicrobial susceptibility pattern was determined by disc diffusion (Kirby- Bauer) method if culture was positive ${ }^{15}$. Standardized commercially available antibiotic discs (Sigma, Germany) of Coamoxiclav, ceftriaxone, ceftazidime, clarithromycin, levofloxacin, meropenem and imipenem were used.

Only immediate or short outcome was observed which was one of the objective of this study. Immediate outcome was defined as outcome of first setting in terms of hospital duration, improvement, referral to ICU, development of complications or mortality outcome during the hospital course. Improvement of the patient means clinical wellbeing, improvement of blood chemistry \& radiological improvement. Pre-designed questionnaire (data sheet) \& consent form were filled up accordingly from all the enlisted patient.

\section{Results}

Statistical analysis was conducted using SPSS version 11 for Windows software. Parametric data were expressed in mean \pm SD. Parametric data were evaluated by independent sample "t" test \& categorical data were evaluated by Chi-squre $\left(\chi^{2}\right)$ test as needed. Level of significance for all analytical test was set as $0.05 \& \mathrm{p}=\leq 0.05$ is considered significant.

\section{Clinico-demographic presentation:}

Total 90 patients with CAP were studied over a period of 10 months. Among them 47 were diabetic and 43 were non-diabetic. Mean age $( \pm$ SD) of the diabetic and non diabetic groups were $56.3( \pm 12.2)$ years and 35.7 $( \pm 10.5)$ years respectively (Table I). Majority of the patients of both groups had respiratory rate $\geq 30 / \min (85.1 \%$ in diabetic group and $62.8 \%$ in non-diabetic groups). Hypotension was noted in about half of the patients of diabetic group $(46.8 \%)$ but only $11.6 \%$ in non-diabetic group. On clinical examination pleural effusion was found in most of the diabetic patients (83.0\%). Presence of consolidation in the lungs was higher in non-diabetic group. All these differences were statistically significant $(\mathrm{p}<0.05)$ (Table I). It was observed that diabetic patients with CAP presented with high E.S.R and BUN in comparison with nondiabetic patients with CAP whereas non-diabetic 
patients with CAP presented with high total count, increased temperature and higher pulse rate than that of diabetic patients with CAP Diabetic patients had significantly higher CURB-65 scoring in comparison with non-diabetic patients $(\mathrm{P}<0.05)$. Comparison of Chest X-ray (CXR) revealed that unilobar infiltration was more common in nondiabetic patients with CAP whereas multilobar infiltrate was more common in diabetic patients with CAP. Pleural effusion with infiltration was more common in diabetic patients with CAP (Table II).

Table I: Clinico-demographic features of the study subjects

\begin{tabular}{|c|c|c|c|c|c|}
\hline \multirow[t]{2}{*}{ Variables } & \multicolumn{2}{|c|}{$\begin{array}{c}\text { Diabetic } \\
(n=47)\end{array}$} & \multicolumn{2}{|c|}{$\begin{array}{c}\text { Non-diabetic } \\
(n=43)\end{array}$} & \multirow[t]{2}{*}{$\begin{array}{c}\mathrm{P} \\
\text { value }\end{array}$} \\
\hline & $\mathrm{n}$ & $\%$ & $\mathrm{n}$ & $\%$ & \\
\hline Sex, Male & 32 & 68.1 & 31 & 72.1 & NS \\
\hline \multicolumn{6}{|c|}{ Age group (in years) } \\
\hline$\leq 40$ & 7 & 14.9 & 24 & 55.8 & NS \\
\hline $41-50$ & 14 & 29.8 & 12 & 27.9 & NS \\
\hline$>50$ & 26 & 55.3 & 7 & 16.3 & NS \\
\hline \multicolumn{6}{|c|}{ Pattern of pneumonia } \\
\hline Atypical & 16 & 34.0 & 6 & 14.0 & \multirow{2}{*}{$0.027^{\mathrm{S}}$} \\
\hline Typical & 31 & 66.0 & 37 & 86.0 & \\
\hline \multicolumn{6}{|c|}{ Respiratory rate/min } \\
\hline$<30$ & 7 & 14.9 & 16 & 37.2 & \multirow[t]{2}{*}{$0.015^{\mathrm{S}}$} \\
\hline$\geq 30$ & 40 & 85.1 & 27 & 62.8 & \\
\hline \multicolumn{6}{|c|}{ Hypotension } \\
\hline Yes & 22 & 46.8 & 5 & 11.6 & \multirow[t]{2}{*}{$0.001^{\mathrm{S}}$} \\
\hline No & 25 & 53.2 & 48 & 88.4 & \\
\hline \multicolumn{6}{|c|}{ Altered mental status } \\
\hline Yes & 25 & 53.2 & 7 & 16.3 & \multirow[t]{2}{*}{$0.001^{\mathrm{S}}$} \\
\hline No & 22 & 46.8 & 35 & 81.4 & \\
\hline \multicolumn{6}{|c|}{ Pleural effusion } \\
\hline Yes & 39 & 83.0 & 13 & 30.2 & \multirow[t]{2}{*}{$0.001^{\mathrm{S}}$} \\
\hline No & 8 & 17.0 & 30 & 69.8 & \\
\hline \multicolumn{6}{|c|}{ Consolidation } \\
\hline Yes & 18 & 38.3 & 36 & 83.7 & \multirow[t]{2}{*}{$0.001^{\mathrm{S}}$} \\
\hline No & 29 & 61.7 & 7 & 16.3 & \\
\hline
\end{tabular}

Table II: Some important characteristics in diabetic and nondiabetic patients with CAP

\begin{tabular}{lcc}
\hline Characteristics & $\begin{array}{c}\text { Diabetic } \\
(\mathrm{n}=47)\end{array}$ & $\begin{array}{c}\text { Non-diabetic } \\
(\mathrm{n}=43)\end{array}$ \\
\hline Temperature $\left({ }^{\circ} \mathrm{F}\right)$, mean $( \pm S D)$ & $100( \pm 1)$ & $102.4( \pm 1)$ \\
Pulse $(/ \mathrm{min})$, mean $( \pm S D)$ & $113( \pm 9)$ & $115( \pm 7)$ \\
BUN $(\mathrm{mmol} / \mathrm{L})$, mean $( \pm S D)$ & $9( \pm 3)$ & $6( \pm 1)$ \\
TC of WBC $(/ \mathrm{cmm})$, mean $( \pm S D)$ & $12900( \pm 2699)$ & $17100( \pm 2906)$ \\
ESR $(\mathrm{mm})$, mean $( \pm S D)$ & $41.5( \pm 13.3)$ & $29.5( \pm 8.3)$ \\
CURB-65 scoring, $n(\%)$ & & \\
$0-1$ & $11(23.4)$ & $27(62.8)$ \\
2 & $9(19.1)$ & $7(16.3)^{*}$ \\
$\geq 3$ & $27(57.4)$ & $9(20.9)$ \\
Chest X-ray findings, $n(\%)$ & & \\
Unilobar infiltrate & $5(10.6)$ & $25(58.1)$ \\
Multilobar infiltrate & $18(38.3)$ & $10(23.3)^{*}$ \\
Pleural effusion with infiltrate & $24(51.1)$ & $8(18.6)$ \\
*P<0.001 & &
\end{tabular}

Growth in sputum culture and antimicrobial sensitivity pattern:

Table III revealed the organism isolated in sputum culture of study subjects. Klebsiella pneumoniae was the most commonly isolated organism from sputum sample. It is followed by Streptococcus pneumoniae, Staphylococcus aureus, E. coli and Pseudomonas aeruginosa. More than one organism was isolated from $7(20.0 \%)$ sputum samples and $1(2.9 \%)$ revealed growth of Acenetobacter. Majority of patients revealed no growth of bacteria in their sputum sample. Antimicrobial sensitivity pattern of isolated organism is presented in Table IV. It was observed that all the 9 isolates $(100 \%)$ of Streptococcus pneumoniae from non-diabetic patients with CAP were sensitive to Co-amoxiclav, Ceftriaxone, Ceftazidime, Imipenem \& Meropenem but $77.8 \%$ sensitive to Clarithromycin and Levofloxacin. All the isolates (100\%) of Klebsiella pneumoniae from diabetic patients with CAP were resistant to Co-amoxiclav, $66.7 \%$ to Levofloxacin, $55.6 \%$ to Clarithromycin and $11.1 \%$ to Ceftriaxone and Ceftazidime. All Klebsiella pneumoniae isolates from non-diabetic patients with CAP were sensitive to Co-amoxiclav, Ceftriaxone and Ceftazidime. All isolates of Staphylococcus aureus from diabetic patients with CAP were sensitive to Ceftriaxone, Imipenem and Meropenem and 50\% sensitive to Ceftazidime, Clarithromycin and Levofloxacin and all were resistant to Coamoxiclav. E. coli were isolated from only diabetic patients. All E. coli isolates were sensitive to Ceftazidime, Imipenem and Meropenem, 50\% to Ceftriaxone and Levofloxacin and all were resistant to Co-amoxiclav. All the Pseudomonas aeruginosa isolates were from diabetic patients with CAP, which were sensitive to Ceftazidime, Imipenem and Meropenem and were resistant to Co-amoxiclav, Ceftriaxone, Clarithromycin and Levofloxacin. Only one isolate of Acinetobacter was from diabetic patient and it was sensitive to Ceftazidime, Ceftriaxone, Imipenem and Meropenem and resistant to Co-amoxiclav, Clarithromycin and Levofloxxacin. More than one organism was isolated from the sputum of $7(20 \%)$ of diabetic patient with CAP. These group of organism were $100 \%$ resistant to Co-amoxiclav, Clarithromycin, levofloxacin and $57 \%$ resistant to Ceftriaxone and Ceftazidime but all (100\%) were sensitive to Meropenem and Imipenem, $42 \%$ sensitive to Ceftriaxone and Ceftazidime.

Table III: Sputum Culture of study subjects

\begin{tabular}{lcccc}
\hline \multirow{2}{*}{ Organism isolated } & \multicolumn{2}{c}{$\begin{array}{c}\text { Diabetic } \\
(\mathrm{n}=47)\end{array}$} & \multicolumn{2}{c}{$\begin{array}{c}\text { Non-diabetic } \\
(\mathrm{n}=43)\end{array}$} \\
\cline { 2 - 5 } & $\mathrm{n}$ & $\%$ & $\mathrm{n}$ & $\%$ \\
\hline Streptococcus pneumoniae & 0 & 0.0 & 9 & 20.9 \\
Klebsiella pneumoinae & 9 & 19.1 & 2 & 4.7 \\
Staphylococcus aureus & 2 & 4.3 & 1 & 2.3 \\
Escherechia coli & 2 & 4.3 & 0 & 0.0 \\
Pseudomonas aeruginosa & 2 & 4.3 & 0 & 0.0 \\
More than one bacteria & 7 & 14.9 & 0 & 0.0 \\
Acinetobacter & 1 & 2.1 & 0 & 0.0 \\
No growth & 24 & 51.1 & 31 & 72.1 \\
\hline
\end{tabular}


Outcome was determined in terms of duration of hospital stay, improvement and mortality. Table V showed the mean duration of hospital stay of two groups of patients. It was observed that mean duration of hospital stay was higher in diabetic group than in non-diabetic group, which was statistically significant $(\mathrm{P}<0.05)$. Table $\mathrm{V}$ also presented the immediate outcome of two groups of study subjects. It was observed that in terms of improvement, $15(31.9 \%)$ and $30(69.8 \%)$ patients improved in diabetic group and non-diabetic group respectively. On the other hand ICU transfer in diabetic patients was higher than that of non diabetic patients with CAP (27.6\% vs $9.3 \%)$. Other complications like empyema, abscess formation were also higher in diabetic subjects. Mortality was also higher in diabetic group with CAP (10.6\%) in comparison with non-diabetic group with CAP $(9.3 \%)$.

Table IV: Sensitivity pattern of isolated bacteria from sputum culture to different antimicrobial agents in both groups

\begin{tabular}{|c|c|c|c|c|c|c|c|c|c|c|c|c|c|c|}
\hline \multirow{4}{*}{$\begin{array}{l}\text { Anti-microbial } \\
\text { agents }\end{array}$} & \multicolumn{14}{|c|}{ Pathogens, n (\%) } \\
\hline & \multicolumn{2}{|c|}{$\begin{array}{l}\text { Streptococcus } \\
\text { pneumoniae }\end{array}$} & \multicolumn{2}{|c|}{$\begin{array}{c}\text { Klebsiella. } \\
\text { pneumoinae }\end{array}$} & \multicolumn{2}{|c|}{$\begin{array}{l}\text { Stapylococcus. } \\
\text { aureus }\end{array}$} & \multicolumn{2}{|c|}{ E. coli } & \multicolumn{2}{|c|}{$\begin{array}{c}\text { Pseudomonas } \\
\text { aeruginosa }\end{array}$} & \multicolumn{2}{|c|}{ Acinetobacter } & \multicolumn{2}{|c|}{ More than one } \\
\hline & $\mathrm{D}$ & ND & $\mathrm{D}$ & ND & $\mathrm{D}$ & ND & $\mathrm{D}$ & ND & $\mathrm{D}$ & $\mathrm{ND}$ & $\mathrm{D}$ & ND & $\mathrm{D}$ & ND \\
\hline & $\mathrm{n}=0$ & $\mathrm{n}=9$ & $\mathrm{n}=9$ & $\mathrm{n}=2$ & $\mathrm{n}=2$ & $\mathrm{n}=1$ & $\mathrm{n}=2$ & $\mathrm{n}=0$ & $\mathrm{n}=2$ & $\mathrm{n}=0$ & $\mathrm{n}=1$ & $\mathrm{n}=0$ & $\mathrm{n}=7$ & $\mathrm{n}=0$ \\
\hline Co-amoxiclav & - & $9(100)$ & $0(0)$ & $2(100)$ & $0(0)$ & $0(0)$ & $0(0)$ & - & $0(0)$ & - & $0(0)$ & - & $0(0)$ & - \\
\hline Ceftriaxone & - & $9(100)$ & $8(89)$ & $2(100)$ & $2(100)$ & $1(100)$ & $1(50)$ & - & $0(0)$ & - & $1(100)$ & - & $3(43)$ & - \\
\hline Ceftazidime & - & $9(100)$ & $8(89)$ & $2(100)$ & $1(50)$ & $1(100)$ & $2(100)$ & - & $2(100)$ & - & $1(100)$ & - & $3(43)$ & - \\
\hline Clarithromycin & - & $7(78)$ & $1(11)$ & $2(100)$ & $1(50)$ & $1(100)$ & $0(0)$ & - & $0(0)$ & - & $0(0)$ & - & $0(0)$ & - \\
\hline Levofloxacin & - & $7(78)$ & $2(22)$ & $1(50)$ & $1(50)$ & $0(0)$ & $1(50)$ & - & $0(0)$ & - & $0(0)$ & - & $0(0)$ & - \\
\hline Meropenem & - & 7 (78) & $9(100)$ & $0(0)$ & $2(100)$ & $0(0)$ & $2(100)$ & - & $2(100)$ & - & $1(100)$ & - & $7(100)$ & - \\
\hline Imipenem & - & $7(78)$ & $9(100)$ & $0(0)$ & $2(100)$ & $0(0)$ & $2(100)$ & - & $2(100)$ & - & $1(100)$ & - & $7(100)$ & - \\
\hline
\end{tabular}

Table V: Immediate Outcome of hospitalized patients

\begin{tabular}{lccc}
\hline Outcome & $\begin{array}{c}\text { Diabetic } \\
(\mathrm{n}=47)\end{array}$ & $\begin{array}{c}\text { Non-diabetic } \\
(\mathrm{n}=43)\end{array}$ & $\begin{array}{c}\mathrm{P} \\
\text { value }\end{array}$ \\
\hline $\begin{array}{l}\text { Duration of hospital stay } \\
\text { (days), mean }( \pm S D)\end{array}$ & $13.5( \pm 2.6)$ & $7.7( \pm 1.7)^{*}$ & \\
$\begin{array}{l}\text { Immediate outcome, n }(\%) \\
\text { Improved }\end{array}$ & $15(31.9)$ & $30(69.8)$ & \\
Deteriorating & $32(68.1)$ & $13(30.2)$ & 0.001 \\
ICU & $13(27.6)$ & $4(9.3)$ & \\
Transfer to other institute & $2(4.2)$ & $1(2.3)$ & \\
Surgical intervention & $4(8.5)$ & $2(4.6)$ & \\
Other complications & $8(17)$ & $2(4.6)$ & \\
Death & $5(10.6)$ & $4(9.3)$ & \\
\hline
\end{tabular}

\section{Discussion}

Many studies carried out on diabetic patients with $\mathrm{CAP}^{\mathbf{1 0 , 1 1 , 1 6}}$, but this study included both diabetic and non-diabetic patients and revealed many interesting findings. Most of the aged diabetic patients presented with atypical pneumonia. Altered mental status and hypotension were the predominant clinical features in diabetic patients with CAP. On the other hand non-diabetic subjects presented with typical respiratory symptoms of pneumonia. This atypical presentation was significantly higher in diabetic group may be due to relatively older age in diabetic patients included in this study ${ }^{3}$.
A Spanish study ${ }^{\mathbf{1 3}}$ found diabetes mellitus (DM) as an independent predictor for the development of pleural effusion. Although their data support our findings but they included DM with co-morbidities in their study whereas we excluded DM with advanced nephropathy and heart failure from our study. This difference of presentation may be due to altered capillary permeability, less vigorous immune response, altered neutrophil and macrophage function of diabetic subjects than nondiabetics. Respiratory rate $\geq 30 / \mathrm{min}$ and presence of hypotension were also common in diabetic patients with CAP. Altered mental status, presence of hypotension higher respiratory rate all favoured aged diabetic patients to make high CURB-65 scoring in comparison with non-diabetic patients with CAP. Mean BUN was higher in diabetic patients. Mean ESR was also higher in diabetic subjects, whereas total count of WBC was lower in DM with CAP subjects in comparison with nondiabetics. A population based cohort study found that there was no difference of BUN and total count of WBC between diabetic and non-diabetic patients when they presented with pneumonia ${ }^{16}$. This data did not support our data.

In our study we could isolate organisms from $38.9 \%$ of sputum samples by culture. A study conducted in Spain $^{\mathbf{1 3}}$ that included sputum culture 
and blood serology as a diagnostic tool could detect $42 \%$ causative pathogen from CAP patients. Other studies could isolate organisms from $46 \%$ patients having CAP. They included both diabetic and nondiabetic patients in their study. Streptococcus pneumoniae was the most frequent causative organism in both DM and non DM patients followed by Haemophilus influenzae, Staph aureus, and other atypical organism like Chlamydia ${ }^{17,18}$. Our findings differ from their study in terms of etiological diagnosis of CAP. The etiology of CAP depends on the geographic areas, the study population and the utilized microbiological lab test ${ }^{17}$. Some important microbiological characteristics came out when we compared two groups of subjects.

Klebsiella pneumoniae was the most frequent isolated organism for the diabetic patients on the other hand Streptococcus pneumoniae was the commonest bacteria causing CAP in non-diabetic subjects. Other bacteria found were Staphylococcus aureus, E. coli and Pseudomonas aeruginosa. More than one organism was also isolated. Most of the Gram negative bacteria were isolated from the sputum of diabetic patients.

We found different groups of bacteria have predilection for causing CAP in two different groups of patients. DM has been associated with many alteration of the immune system. There is significant changes within humoral and cell mediated immunity, particularly related to the neutrophil function, pulmonary function abnormality such as reduction of diffusion capacity in diabetic patients having signs of microangiopathy ${ }^{19}$. In relation to pulmonary infection, the few available studies suggest this alteration of immune system in diabetic patients but do not prove certain association between DM and susceptibility by uncommon microorganism ${ }^{\mathbf{2 0 , 2 1}}$.

Our study disclosed sensitivity pattern of isolated strain of bacteria from diabetic and non-diabetic CAP patients. It is alarming that resistant bacteria are emerging from both groups of patients, specially the strain isolated from the sputum of diabetic patients. It was observed that isolated Klebsiella pneumonia strain from diabetic patients was mostly resistant to commonly used antibiotics for CAP. Other isolated organisms like Staphylococcus aureus, Pseudomonas aeruginosa, E.coli from diabetic patients with CAP were also resistant to $\square$-lactamase inhibitor, Macrolides and third generation cephalosporin.

Streptococcus pneumoniae mostly isolated from non-diabetic patients were sensitive to commonly used antibiotics for CAP. Our study also revealed
Carbapenems i.e. Imipenem, Meropenem as the most effective antibiotic for CAP. These antibiotics are costly and not recommended by the guideline published by American thoracic society and Infectious disease society of America ${ }^{22,23}$. Betalactam antibiotics and Macrolides are used as the first line regimen for the treatment CAP in our country but emerging strains are more resistant to these conventional antibiotics. A study of International Centre for Diarrhoeal Diseases Research, Bangladesh (ICDDR,B) found Pneumococcus serotype resistant to penicillin \& macrolides posing threat to Bangladesh and some other Asian countries ${ }^{24}$.

We evaluated the immediate outcome of CAP patients between diabetic and non-diabetic. Immediate outcome was assessed on the basis of duration of hospital stay, improvement, transfer to ICU or other institution, surgical intervention and other complications like empyema, abscess formation and mortality outcome. It was observed that hospital duration, ICU transfer and development of complications were significantly higher in diabetic patients than that of nondiabetics. On the other hand improvement during hospital discharge in non diabetic with CAP is more in comparison with Diabetic. Pneumonia severity scoring was done (CURB-65) in all patients and significantly higher scoring was found in diabetic patients.

In conclusion, clinical presentation, microbial characteristics, antimicrobial susceptibility and immediate outcome of CAP differed in diabetics and non-diabetics. Frequency of atypical presentation and CURB-65 score were significantly higher in diabetics. Klebsiella pneumoniae was the most frequent causative pathogen for CAP in diabetic patients, whereas Streptococcus pneumoniae was the most frequent causative agent for non-diabetic patients. Bacteria isolated from sputum sample of CAP with diabetes were resistant to almost all recommended antibiotics used for CAP but $100 \%$ isolates were sensitive to Carbapenems. Pulmonary complications were relatively more in diabetics and they required referral to intensive care unit more than that of nondiabetics. So, diabetic patients with CAP require extra attention.

\section{References}

1. Chestnut MS, Murry JA, Prendergast TJ. Pulmonary disorder. In: McPheeSJ, Papadakis MA. Current Medical Diagnosis and Treatment. $48^{\text {th }}$ ed. New York: Mc Graw Hill; 2009: p. 239

2. Lutfiyya MN, Henley E, Chang LF. Diagnosis and treatment of Community acquired pneumonia. Am Fam Physician 2006; 73: 442-50. 
3. Innes JAA, Reid PT. Respiratory diseases. In: Boon NA, Colledge NR, Walker BR, Hunter JAA Davidson's Principles \& Practice of Medicine. $20^{\text {th }}$ ed. London: Churchill Livingstone; 2006: p. 689

4. World Health Organization \& International Diabetes Federation. Definition and diagnosis of diabetes mellitus and intermediate hyperglycaemia: Report of a WHO/IDF consultation. World Health Organization. Geneva: 2006.

5. Mahtab H. Definition, diagnostic criteria \& classification of Diabetes mellitus. In: Mahtab H, Latif ZA, Pathan MF. Diabetes Mellitus-A handbook for professionals. $4^{\text {th }}$ ed. Dhaka: Diabetic Association of Bangladesh; 2007: pp. 5-10.

6. Valerius $\mathrm{NH}$, Eff $\mathrm{C}$, Hansen NE, Ganong RP. Neutrophil and lymphocyte function in Diabetes mellitus. Acta Med Scand 1982; 211: 463-72.

7. Chang FY, Shaio MF. Decreased cell-mediated immunity in patients with non-insulin-dependent diabetes mellitus. Diabetes Res Clin Pract 1995;28: 137- 46.

8. Geerlings SE, Hoepelman AI. Immune dysfunction in patients with diabetes mellitus. FEMS Immunol MED MIcrobiol 1999; 26: 259-65.

9. Vracko R, Thorning D, Huang TW. Basal lamina of alveolar epithelium and capillaries: quantitative change with aging in diabetes mellitus. Am Rev Respir Dis 1979; 120: 973- 83.

10. Ljubic S, Balachandran A, Pavlic-Rener I, BArada A, Metelko Z. Pulmonary infections in diabetes mellitus. Diabetol Croatica 20004; 33: 115- 23.

11. Lipsky BA, Pecoraro RE, Chen MS, Koepsel TD. Factors affecting Staphylococcal colonization among NIDDM out-patients. Diabetes Care 1987; 10: 483-5.

12. Potgieter PD, Hammond JM. Etiology and diagnosis of pneumonia requiring ICU admission. Chest 1992; 101: 199- 203.

13. Falugera M, Pifarre R, Martin A, Shheikh A, Moreno A. Etiology and outcome of community aacquired pneumonia in patients with diabetes mellitus. Chest 2005; 128: 3233- 9 .

14. Valencia M, Badia JR, Cavalcanti $M$ et al. Pneumonia severity index class $\mathrm{v}$ patients with communityacquired pneumonia: characteristics, outcomes, and value of severity scores. Chest 2007; 132: 515- 22.
15. Miles RS, Amyes SGB. Laboratory control of antimicrobial therapy. In Colle JG, Fraser AG, Marmion BP (ed), Simmons A. Mackie \& McCartney Practical Medical Microbiology. $14^{\text {th }}$ ed. Churchill Livingstone, London 1996. Pp. 151-78.

16. Kornum JB, Thomsen RW, Riis A, Lervang HH, Schønheyder HC, Sørensen HT. Type 2 Diabetes and pneumonia outcome. Diabetes Care 2007; 30: 2251-7.

17. Sohn JW, Park SC, Choi YH et al. Atypical pathogens as etiologic agents in hospitalized patients with community acquired pneumonia in Korea: a prospective multicenter study. J Korean Med Sci 2006; 21: 602-7.

18. Ruiz M, Ewig S, Marcos MA et al. Etiology of community acquired pneumonia: impact of age, comorbidity and severity. Am J Respir Crit Care Med 1999; 160: 397-405.

19. Joshi N, Caputo GM, Weitekamp MR, Karchmer AW Infections in patients with diabetes mellitus. N Engl J Med 1999; 341: 1906-12.

20. Koziel H, Koziel MJ. Pulmonary complications of diabetes mellitus- pneumonia. Infect Dis Clin North Am 1995; 9: 65-96.

21. Ardigo D, Valtuena S, Zavaroni I, Baroni MC, Delsignore R. Pulmonary complications of diabetes mellitus: the role of glycaemic control. Curr Drug Targets Inflamm Allergy 2004; 3: 455-8.

22. Mandell LA, Wunderink RG, Anzueto A et al. Whitney CG. Infectious disease society of America/ American Thoracic society Consensus guideline on the management of community acquired pneumonia in adult. Clin Infect Dis 2007; 44 Suppl 2: S27-72.

23. American thoracic Society and the Infectious Disease society of America. Guidelines for the Management of Adults with Hospital-acquired, Ventilator-associated, and Healthcare-associated Pneumonia. Am J Respir Crit Care Med 2005; 171: 388-416.

24. Rahman M, Hossain S, Shoma S et al. Emergence of a unique multiple antibiotic resistant staphylococcus pneumonia-serotype 7B clone in Dhaka, Bangladesh. J Clin Microbiol 2006; 44: 4625-7. 